\title{
Advokasi Penerapan Kawasan Tanpa Rokok di Sekolah
}

\section{Advocacy for the Implementation of No Smoking Areas in Schools}

\author{
Annisa Sayyidatul Ulfa ${ }^{1}$, Rita Damayanti ${ }^{1}$
}

${ }^{1}$ Departemen Pendidikan Kesehatan dan Ilmu Perilaku, Fakultas Kesehatan Masyarakat, Universitas Indonesia, Kampus UI Depok 16424, Indonesia

*Korespondensi penulis:

annisayyidatulfa@gmail.com
Diterima (Recieved)

Direvisi (Revised)

Diterima untuk diterbitkan (Accepted)
: 23 Desember 2021
$: 26$ Desember 2021
$: 27$ Desember 2021

\section{ABSTRAK}

Latar Belakang. Jumlah perokok pasif di Indonesia mencapai $75 \%$ atau 96,9 juta orang. Sebanyak 66,2\% pelajar terpapar rokok di ruang publik tertutup. Kementerian Pendidikan dan Kebudayaan telah menerbitkan Permendikbud 64/2015 tentang Kawasan Tanpa Rokok (KTR) di Lingkungan Sekolah. Masih perlu optimalisasi pelaksanaan KTR di sekolah.

Tujuan. untuk melihat bagaimana peran siswa dalam proses advokasi dalam mengimplementasikan KTR di sekolah

Metode. Penelitian ini merupakan penelitian deskriptif kualitatif dengan desain studi kasus yang dilakukan di suatu SMP di Kabupaten Bogor. Terdapat 7 informan yang terlibat. Teknik pengumpulan data yang digunakan adalah Focus Group Discussion (FGD) dan wawancara mendalam dengan melihat proses advokasi menggunakan Kerangka Advokasi "A".

Hasil. Siswa berperan sebagai pelaksana KTR di sekolah dengan mengadvokasi guru untuk menjadi fasilitator siswa, pimpinan sekolah sebagai pembuat kebijakan, dan pedagang toko di sekitar sekolah. Siswa mengidentifikasi permasalahan yang dirasakan, merumuskan strategi, menganalisis target dan melakukan advokasi. Kesepakatan yang terbentuk diantaranya pelaksanaan KTR sesuai kemampuan dan kondisi sekolah, pemasangan plang KTR, menjalankan satgas KTR, sosialisasi bahaya merokok dan advokasi kepada warung di sekitar sekolah untuk menurunkan spanduk iklan rokok.

Kesimpulan. Siswa bisa menjadi agen perubahan untuk implementasi KTR di sekolah dengan adanya fasilitasi dan dukungan dari guru dan kepala sekolah.

Kata Kunci: peran siswa; advokasi; Kawasan Tanpa Rokok (KTR) Sekolah

\begin{abstract}
Background. Passive smokers in Indonesia reaches $75 \%$ or 96.9 million people. $66.2 \%$ students are exposed to cigarette in closed public spaces. Ministry of Education and Culture issued Permendikbud 64/2015 concerning KTR in the School Environment. implementation of KTR in schools still need optimization.

Objective to see how the role of students in the advocacy process in implementing schools as smoke-free areas. Method. This research is a qualitative descriptive research with case study design conducted in a Junior High School of Bogor Regency. There were 7 informants. The data collection technique used Focus Group Discussion (FGD) and in-depth interviews by looking at the advocacy process using the "A" Advocacy Framework.

Results. Students act as implementers of KTR in schools by advocating teachers to become student facilitators, school leaders as policy makers, and shop traders around the school. Students identify perceived problems, formulate strategies, analyze targets and conduct advocacy. The agreement formed include implementation of KTR according to the school's ability and condition, installing KTR signs, applying KTR task-force and advocating stalls around schools to put down cigarette advertising banners

Conclusion. Students can become agents of change for the implementation of KTR in schools with facilitation and support from teachers and principals.
\end{abstract}

Keywords: student role; advocacy; smoke free school 


\section{LATAR BELAKANG}

Indonesia termasuk negara dengan perokok tertinggi ketiga sebesar 53,7 juta orang, setelah China dan India. ${ }^{1}$ Menurut data Profil Kesehatan Ibu dan Anak, angka perokok Indonesia pada tahun 2020 sebesar $28,69 \% .^{2}$ Selain itu, berdasarkan data Riset Kesehatan Dasar (Riskesdas) 2018 angka perokok anak usia 10-18 tahun adalah 9,1\% atau sekitar 3,2 juta anak. ${ }^{3}$ Hal tersebut menjadi sebuah masalah terhadap pengaturan pengendalian rokok di Indonesia.

Peningkatan jumlah perokok aktif tersebut secara tidak langsung meningkatkan jumlah perokok pasif yang menghirup asap rokok atau biasa disebut secondhand smoker. Berdasarkan Global Youth Tobacco Survey (GYTS) menunjukkan bahwa $57,8 \%$ pelajar terpapar asap rokok di rumah dan $66,2 \%$ di ruang publik tertutup. ${ }^{4}$ Perokok pasif di Indonesia masih menjadi masalah yang cukup serius. Berdasarkan data Riskesdas 2013, jumlah perokok pasif di Indonesia sebanyak $75 \%$ atau 96,9 juta jiwa, yang mana $68,8 \%$ adalah perempuan. ${ }^{5}$ Angka ini berkebalikan dengan angka perokok aktif yang didominasi oleh laki-laki. Perokok pasif tersebut juga dirasakan oleh balita yang tidak merokok. Balita termasuk kedalam kelompok rentan, akan tetapi harus menjadi korban asap rokok orang lain dengan angka yang tidak kecil yaitu sebanyak 12 juta balita 0-4 tahun. ${ }^{5}$

Untuk memperkuat pengamanan terhadap perokok pasif, pemerintah menerbitkan Peraturan bersama Kementerian Kesehatan dan Kementerian Dalam Negri no 7 tahun 2011 tentang Pedoman Pelaksanaan Kawasan Tanpa Rokok (KTR) serta Peraturan Kementerian Pendidikan dan Kebudayaan no 64 tahun 2015 tentang Kawasan Tanpa Rokok di Lingkungan Sekolah. ${ }^{6}$ Peraturan di atas juga didukung implementasinya oleh daerah-daerah yang sudah memiliki Peraturan Daerah tentang Kawasan Tanpa Rokok seperti Perda Kabupaten Bogor No. 8 Tahun 2016, yang mana salah satu KTR yaitu tempat proses belajar mengajar. $^{7}$

Diketahui berdasarkan hasil penelitian sebelumnya bahwa implementasi KTR di sekolah dapat mengurangi kebiasaan merokok di lingkungan sekolah. ${ }^{8}$ Akan tetapi, pada peneli- tian lain disebutkan bahwa implementasi KTR di SMP sederajat masih belum maksimal karena warga sekolah masih ada yang merokok di lingkungan sekolah, dan belum ada komitmen secara tegas untuk menegakkan KTR. ${ }^{9}$ Dalam penelitian lain disebutkan bahwa untuk mendukung sebuah program pada institusi pendidikan, perlu adanya kebijakan dan dukungan penerapan KTR dari mahasiswa dan organisasi kemahasiswaan. ${ }^{10}$ Penelitian ini bertujuan untuk melihat peran siswa dalam proses advokasi dalam mengimplementasikan sekolah sebagai kawasan tanpa rokok khususnya pada jenjang SMP.

\section{METODE}

Jenis penelitian ini merupakan deskriptif kualitatif dengan desain penelitian studi kasus. Informan penelitian ini adalah kepala sekolah, guru BK, dan anggota dari Organisasi Siswa Intra Sekolah (OSIS), ekstrakurikuler pramuka, futsal dan marawis. Penelitian ini dilakukan dengan teknik pengumpulan data Focus Group Discussion (FGD) dan wawancara mendalam terhadap informan. Peserta FGD merupakan lima orang siswasiswi perwakilan dari anggota organisasi, sedangkan informan wawancara mendalam yaitu kepala sekolah dan guru BK. Penelitian ini menggunakan " $A$ " Framework for Advocacy oleh John Hopkins University, (1999), yang mana dalam konsep ini ada enam langkah yang digunakan untuk advokasi ${ }^{11}$, yaitu Analisis, Strategi, Mobilisasi, Aksi, Evaluasi, serta Keberlanjutan.

\section{HASIL}

Berdasarkan hasil FGD dengan siswasiswi perwakilan dari organisasi intra sekolah, disusunlah rencana aksi untuk advokasi implementasi sekolah sebagai KTR. Rencana aksi ini disusun berdasarkan analisis situasi masalah dan dampak yang dirasakan oleh para siswa, lalu strategi advokasi yang bisa dilakukan untuk menjadi solusi dari masalah yang ada, serta rencana aksi dan waktu pelaksanaannya. Mobilisasi sasaran advokasi juga dianalisis pada tahap ini.

Analisis masalah merupakan langkah pertama yang harus dilakukan guna mengidentifikasi isu yang akan diambil untuk aksi 
yang akan dilakukan. ${ }^{12}$ Analisis masalah pada kondisi sekolah yaitu (a) Masih ada orang yang merokok di sekolah; (b) Masih ada asap rokok; (c) Masih ada bau asap rokok; (d) Masih ada penjualan rokok; dan (e) Masih ada iklan rokok. Analisis masalah yang dilakukan tersebut dibandingkan dengan lima indikator kawasan tanpa rokok yang ada pada Permendikbud Nomor 64 Tahun $2015^{13}$ yang meliputi: (a) adanya larangan merokok dalam aturan sekolah; (b) tidak bekerjasama dalam hal iklan, promosi dan sponsor rokok; (c) memberlakukan larangan pemasangan iklan rokok di lingkungan sekolah; (d) melarang penjualan rokok di kantin/warung sekolah atau di lingkungan sekolah; serta (e) memasang tanda kawasan tanpa rokok di lingkungan sekolah. Berdasarkan analisis indikator tersebut, sekolah baru mencapai satu dari lima indikator KTR yang dilaksanakan, sehingga dalam penegakan KTR perlu adanya strategi guna meningkatkan implementasi KTR yang lebih baik.

Perencanaan strategi pada advokasi ini dilakukan untuk membantu pada proses mengubah perilaku dalam menanggapi kondisi lingkungan yang terjadi pada saat penelitian ini, strategi advokasi ini disusun secara komprehensif berdasarkan masalah yang ada, mampu dan mungkin untuk dilakukan oleh sasaran, serta disusun secara sistematis, taktis dan berani. ${ }^{14,15}$ Hal tersebut sesuai dengan prinsip advokasi. ${ }^{10}$ Hasil strategi yang telah disusun adalah Melakukan edukasi bahaya rokok; (2)
Membuat Satgas Penerapan KTR; (3) Pemasangan plang dan stiker KTR; (4) Kompromi/komplain pelarangan penjualan rokok ke anak sekolah; serta (5) Pencopotan/ penggantian banner rokok dengan banner yang lebih menarik.

Mobilisasi dilakukan dengan cara menghimpun pihak yang memiliki kepentingan terhadap advokasi ini, yaitu: Kepala sekolah; Pembina Osis; Ketua Osis; Guru BK; serta Pemilik warung sekitar sekolah. Kegiatan yang direncanakan untuk proses advokasi ini adalah diskusi dengan guru (4 Oktober 2020); Advokasi kepada kepala sekolah (18 Oktober 2020); Pemasangan plang dan sticker KTR; Diskusi dengan pemilik warung, kepala sekolah dan guru; serta persiapan untuk pencopotan banner pengganti. Kegiatan tersebut diberi batas waktu hingga akhir Desember 2020. Pada pelaksanaannya, anak-anak mengawali menyampaikan hasil analisis strategi mereka kepada guru secara daring. Kemudian bersama dengan guru, mereka menyampaikan kepada kepala sekolah secara daring dan beberapa perwakilan secara luring. Pemasangan plang dilakukan setelah proses siswa mengadvokasi hingga kepala sekolah pada tanggal 16 November 2020 atas persetujuan ketua yayasan dan kepala sekolah. Pertemuan dengan pemilik warung dilakukan pada tanggal 28 Januari 2021, namun pemilik warung tidak menyetujui untuk melepaskan banner iklan rokok pada warungnya.

Tabel 1. Analisis, Strategi, Mobilisasi dan Aksi

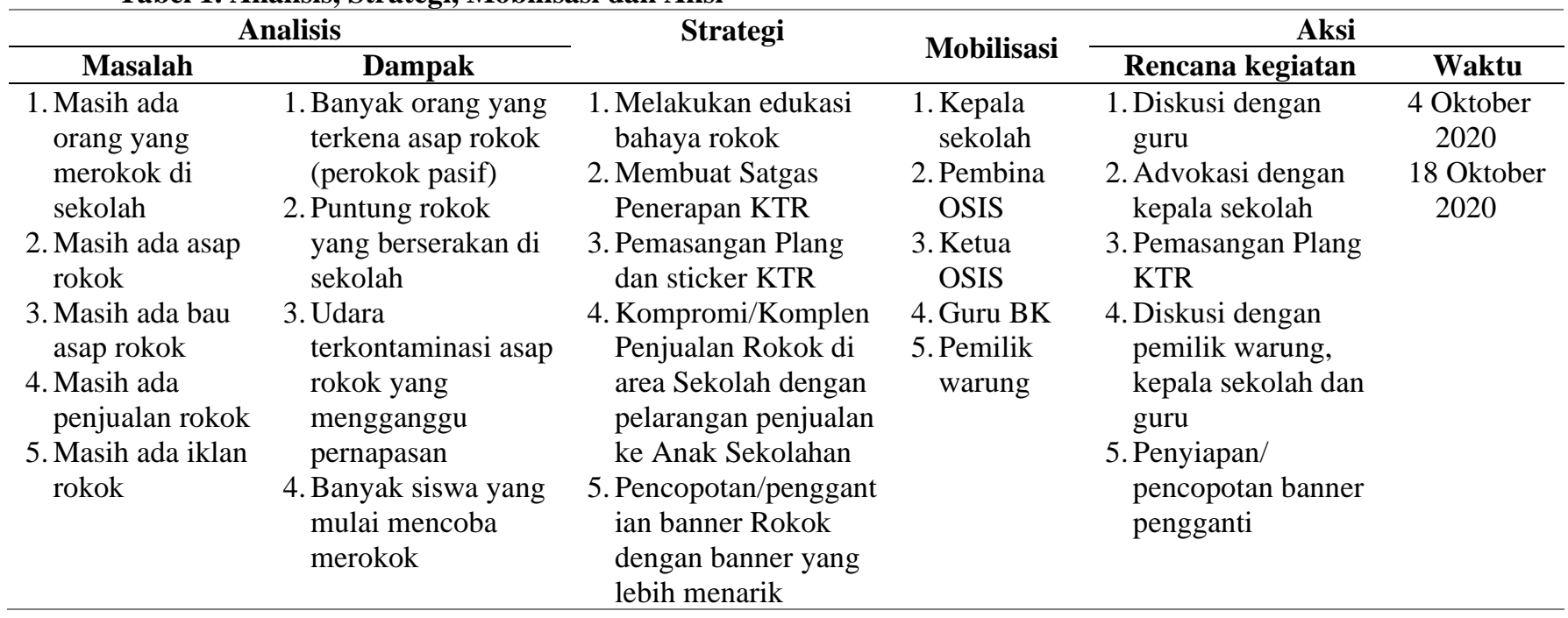




\section{Evaluasi}

Sejak penerapan dan pemasangan KTR di sekolah, guru diberikan pengetahuan yang sama tentang informasi KTR tersebut. Banyak guru yang ikut mendukung dalam penerapan KTR di sekolah. Walaupun demikian, masih ada guru yang melanggar dengan tetap merokok di kawasan sekolah. Dalam penerapan KTR di sekolah, orang tua siswa dan tukang yang sedang merenovasi sekolah merupakan orang-orang yang belum terinformasi dengan baik tentang KTR di sekolah. Masih ada orang tua yang ketika datang ke sekolah untuk mengambil rapor, mereka merokok di sekolah. Namun, guru BK dan guru lainnya yang sudah terinformasi dan sepakat, menegur hal tersebut demi penegakan KTR di sekolah yang komprehensif.

Selain itu yang menjadi tantangan dalam penerapan KTR adalah ketua yayasan sekolah yang juga seorang perokok. Ketika ketua yayasan berkunjung ke sekolah dan melihat ada plang KTR, sedang beliau merupakan seorang perokok, beliau masih tetap merokok di kawasan sekolah. Karena hal tersebut merupakan pelanggaran, guru BK yang sudah berkomitmen dalam menegakkan KTR di sekolah menegur ketua yayasan dengan menunjukkan plang KTR dan menyebutkan bahwa di sekolah merupakan kawasan tidak boleh merokok. Akan tetapi, dengan power yang dimiliki oleh ketua yayasan, beliau memindahkan plang KTR tersebut ke gedung 2 yang bersebelahan dengan gedung 1 namun berbeda pagar. Hal tersebut dinyatakan sebagai kawasan tanpa rokok berada di gedung dua saja, tidak di gedung satu.

Akhirnya, sebagai bentuk antisipasi dan evaluasi dari kejadian di atas, guru BK dibantu oleh siswa-siswa memasangkan stiker KTR di seluruh kelas dan ruang guru yang ada di gedung 1. Sebelumnya stiker tersebut tidak dipasang karena merasa belum perlu. Berdasarkan kejadian di atas, menjadi bahan pertimbangan sekolah untuk menempelkan stiker agar semua warga sekolah yang berkunjung bisa melihat informasi KTR dan selalu teringatkan untuk tidak merokok di kawasan sekolah.

\section{Keberlanjutan pelaksanaan KTR di sekolah}

Sebagai bentuk keberlanjutan penerapan KTR di sekolah, di sini anak-anak dan guru BK yang saat ini juga menjadi pembina OSIS di sekolah, berkomitmen penuh dengan penegakan KTR di sekolah. Anak-anak yang tergabung dalam OSIS kemudian melakukan edukasi pada kegiatan LDKS untuk anggota OSIS yang baru. Kegiatan ini bertujuan untuk menginformasikan bahaya rokok dan adanya KTR di sekolah sebagai tindak lanjut serta kaderisasi satgas KTR di sekolah pada tanggal 27 februari 2021. Hal tersebut dikawal oleh pembina OSIS dan didukung oleh kepala sekolah sebagai bentuk komitmen terhadap penegakan KTR di sekolah. Selain itu, direncanakan pula sosialisasi yang sama untuk siswa baru pada MPLS mendatang dengan metode peer educator yang akan dilakukan oleh anggota OSIS. Hal tersebut dilakukan guna menginformasikan komitmen sekolah dalam penerapan KTR agar siswa baru bisa mengikuti dan menyepakati aturan KTR di sekolah dengan informasi yang lengkap.

\section{PEMBAHASAN}

Berdasarkan analisis masalah, dampak masalah yang diangkat dari tidak adanya penegakan KTR di sekolah adalah (a) banyak orang yang terkena asap rokok (perokok pasif); dan (b) Udara terkontaminasi asap rokok yang mengganggu pernapasan. Hal tersebut sejalan dengan hasil penelitian Kiyoung bahwa pada sekolah menengah di pedesaan kecil, aktivitas merokok di sekolah mengakibatkan terpaparnya polusi udara tingkat tinggi yang berbahaya. ${ }^{16}$ Selain itu, dampak dari lingkungan sekolah yang tidak KTR adalah (c) Puntung rokok yang berserakan di sekolah; serta (d) banyak siswa yang mulai mencoba merokok, hal tersebut telah dibuktikan oleh penelitian sebelumnya bahwa, lingkungan rumah yang merokok mempengaruhi perilaku, penerimaan, kerentanan, keyakinan dan motivasi untuk merokok pada remaja. ${ }^{17}$

Pada hasil strategi yang telah disusun tersebut, sudah sesuai dengan Principle of Ecological Model, yang mana disebutkan bahwa model ekologi ini merupakan petunjuk kemajuan dari penelitian promosi kesehatan 
remaja. ${ }^{18}$ Model ekologi dalam strategi ini menguatkan pada tingkat intrapersonal, interpersonal, institutional, community, dan public policy. ${ }^{19}$ Model ekologi ini terdiri empat prinsip. ${ }^{20}$ Prinsip pertama yaitu bisa mempengaruhi perilaku secara mikro hingga makro. Hal ini ditandai dengan tingkat sasaran strategi advokasi yang menyasar level siswa untuk edukasi tentang bahaya rokok dan KTR (intrapersonal) hingga level pemegang kebijakan tertinggi untuk menerapkan peraturan KTR di sekolah (public policy). Prinsip kedua pada tingkat model dalam interaksi. Siswa dan guru yang memiliki motivasi tinggi terhadap KTR, bisa memengaruhi lingkungan yang juga mendukung terhadap penerapan KTR di sekolah. Prinsip selanjutnya dalam model ekologi ini harus membuat dampak yang besar. Pada analisis sebelumnya, telah disusun dampak yang bisa terjadi jika kegiatan merokok di sekolah terus dilakukan. Oleh karena itu, adanya penerapan KTR ini, diharapkan bisa berkontribusi atas dampak yang mungkin dihasilkan. Prinsip yang terakhir yaitu perilaku yang spesifik. Pada strategi ini, dilakukan implementasi KTR di sekolah dengan melakukan edukasi serta pengkondisian guna mencegah perilaku merokok di lingkungan sekolah.

Selain menggunakan prinsip model ekologi, strategi implementasi KTR di sekolah ini juga sesuai dengan kerangka PRECEDE/ PROCEED dari Green and Kreuter 2005. ${ }^{21}$ Dalam kerangka PRECEDE/PROCEED dapat digunakan untuk menerapkan pengendalian tembakau. $^{22}$ Berdasarkan kerangka tersebut, perubahan perilaku bisa dicapai dengan tiga faktor yaitu, predisposisi, pemungkin dan pendorong. Faktor predisposisi pada strategi ini yaitu dalam peningkatan pengetahuan siswa dan warga sekolah terkait KTR dengan adanya edukasi dan sosialisasi guna memperkuat dalam pencegahan perilaku merokok di lingkungan sekolah. Faktor kedua yaitu pemungkin, strategi pada penelitian ini, diusulkan untuk mengadvokasi warung terdekat untuk tidak menjual dan memasak spanduk iklan rokok, serta memasang plang KTR, untuk mendukung adanya lingkungan sekolah yang bebas dari akses rokok yang mudah serta iklan rokok. Faktor terakhir yaitu adanya dukungan sekolah dengan memberikan izin serta membuat satgas KTR dalam penegakkan KTR di lingkungan sekolah.

\section{KESIMPULAN}

Proses advokasi yang melibatkan siswa dalam implementasi kebijakan sekolah sebagai kawasan tanpa rokok yaitu siswa bisa menganalisis sederhana terkait masalah yang ada, membuat stretegi sederhana yang akan dilakukan serta melakukan audiensi kepada guru dan kepala sekolah sehingga siswa bisa menjadi agen perubahan untuk implementasi KTR di sekolah. Hal tersebut bisa terjadi jika siswa difasilitasi dan didukung oleh guru dan kepala sekolah.

\section{SARAN}

Pemerintah, institusi pendidikan serta pegiat pengendalian tembakau sebaiknya melibatkan siswa dalam proses penerapan KTR di sekolah dengan mengkapasitasi, mendampingi dan mendorong siswa mengenai KTR.

\section{UCAPAN TERIMA KASIH}

Penulis mengucapkan terima kasih kepada SMP Mahardika yang sudah bersedia terlibat dalam proses penelitian ini dan kepada Yayasan Lentera Anak dan Yayasan Plan Internasional Indonesia karena sudah memfasilitasi penelitian ini.

\section{DAFTAR REFERENSI}

1. WHO. Prevalence Tobacco Atlas. 2018.

2. Saputra R. Profil Kesehatan Ibu Dan Anak 2020. J Chem Inf Model. 2020;53(9):1689-99.

3. Badan Penelitian dan Pengembangan Kesehatan. Riset Kesehatan Dasar (Riskesdas) Tahun 2018 [Internet]. Badan Penelitian dan Pengembangan Kesehatan. 2018. p. 198. Available from:

http://labdata.litbang.kemkes.go.id/ima ges/download/laporan/RKD/2018/Lapo ran_Nasional_RKD2018_FINAL.pdf

4. GYTS. Lembar Informasi Indonesia 
2019 (Global Youth Tobacco Survei). World Heal Organ. 2020;1-2.

5. Kusnandar VB. 96 Juta Orang Indonesia Jadi Perokok Pasif | Databoks. 2019.

6. Menkumham RI. SKB Menkes Dan Mendagri::Pedoman Pelaksanaan Kawasan Tanpa Rokok (KTR)::BN 492011. 2011.

7. Sekda Kabupaten Bogor. Peraturan Daerah No 8 Tahun 2016 tentang Kawasan Tanpa Rokok. 2016.

8. Kuipers MAG, de Korte R, Soto VE, Richter M, Moor I, Rimpelä AH, et al. School smoking policies and educational inequalities in smoking behaviour of adolescents aged 14-17 years in Europe. $\mathbf{J}$ Epidemiol Community Health. 2015;70(2):132-9.

9. Marchel YA. Implementasi Kawasan Tanpa Rokok Sebagai Pencegahan Merokok Pada Remaja Awal. J PROMKES. 2019;7(2):144.

10. Trisnowati H. Peran Mahasiswa dalam Penerapan Kawasan Tanpa Rokok. 2016;(May).

11. Pratomo H. ADVOKASI: Konsep, Teknik dan Aplikasi di Bidang Kesehatan di Indonesia. Jakarta: Rajawali Pers; 2015.

12. Sharma RR. An Introduction to Advocacy: Training Guide. Vol. 29. USAID; 1997. 300-301 p.

13. Mendikbud RI. Peraturan Menteri Pendidikan dan Kebudayaan Republik Indonesia Nomor 64 Tahun 2015 tentang Kawasan Tanda Rokok di Linkungan Sekolah. 2015;

14. Giesecke J. Practical strategies for library managers. American Library Association; 2001.

15. Bryson JM, Edwards LH, Van Slyke DM. Public Management Review Getting strategic about strategic planning research. 2017;

16. Lee K, Hahn EJ, Riker CA, Hoehne A, White A, Greenwell D, et al. Secondhand Smoke Exposure in a Rural High School. 2007;23(4).

17. Muilenburg JL, Latham T, Annang L, Johnson WD, Burdell AC, West SJ, et al. The home smoking environment: Influence on behaviors and attitudes in a racially diverse adolescent population. Heal Educ Behav. 2009;36(4):777-93.

18. Wold B, Mittelmark MB. Healthpromotion research over three decades: The social-ecological model and challenges in implementation of interventions. Scand J Public Health. 2018 Feb;46(20_suppl):20-6.

19. Nutland W, Cragg L. Understanding Public Health: Health Promotion Practice. Second. Open University Press; 2015.

20. Sharma M, Branscum P, Atri A. Introduction to Community and Public Health, John Wiley \& Sons, Incorporated. First Edit. San Francisco: Jossey Bass; 2014.

21. Porter CM. Revisiting PrecedeProceed: A leading model for ecological and ethical health promotion. Health Educ J. 2016;75(6):753-64.

22. Gielen AC, Green LW. The Impact of Policy, Environmental, and Educational Interventions: A Synthesis of the Evidence From Two Public Health Success Stories. Heal Educ Behav. 2015 Apr;42(1_suppl):20-34. 